\title{
The Cognitive Motivations of Fictive Motion from the Perspective of Phenomenology
}

\author{
Shi Lihong \\ Foreign Language Department, Beijing Institute of Graphic Communication \\ Beijing, 102600, China
}

\begin{abstract}
This paper tries to approach the cognitive motivations from a new perspective: phenomenology. It first reviews the cognitive motivations of fictive motion proposed by Talmy, Langacker, Lakoff and Turner, Fauconnier, and Matlock, whose explanations are widely accepted in this field. Then, it expounds the phenomenology and proposes three cognitive motivations of fictive motion expressions from the perspective of phenomenology: interaction between experience and language, intersubjectivity and imagination.
\end{abstract}

Keywords-Fictive motion; Cognitive motivation; Phenomenology; Intersubjectivity

\section{INTRODUCTION}

In recent years, the linguistic phenomenon that the use of sentences with motion verbs denotes states with, at least from surface, no motions has attracted much attention of researchers in cognitive semantics. Eg:

(1) That mountain range goes all the way from Canada to Mexico.

(2) The road runs through the dessert.

(3) Light shone from the sun into the cave.

(4) He was uplifted by her smile.

In the 4 examples, motion verbs are utilized to denote the motionless objects without life such as mountain ranges, the road, and the light. Light may travel from the perspective of physics, but its motion still is beyond the human vision. This recurrent linguistic phenomenon seems universal in most languages. It was termed as fictive motion [1] and subjective motion [2-4] or abstract motion [5]. This paper will follow Talmy and adopt the term fictive motion since his categorization of fictive motion is widely accepted and has been regarded as the foundation of fictive motion research. According to Talmy, fictive motion is the cognitive bias towards dynamism [1]. But Langacker instead attributes the motion aspect of fictive motion expressions to the subjective motion on the part of the conceptualizer. So, different linguists pose different cognitive motivations for fictive motion expressions. This paper will review the widely accepted cognitive motivations first and then discuss a new motivation on fictive motion from the perspective of phenomenology proposed by Blomberg and Zlatev [6-8].

\section{FICTIVE MOTION}

As the one of the founders of cognitive semantics, Talmy is among the first researchers who have systematically explored into fictive motion. Talmy first mentioned fictive motion in his paper "Figure and ground in complex sentences" published in 1978. He thinks sentences of spatial relationships and motion events are spatial-temporal homologies [9]. He expounded the system of spatial concepts in detail in "How language structure space" published in 1983. In 1996, Talmy divided the linguistic representations into two types in terms of their differences in visual representations. If the linguistic representations in the literal sense highly conform to the visual images in observers' eyes, then they are classified as factual representations. If the conformity is low, they are called fictive representation, like the utilization of motion verbs to depict the motionless state of an object. Talmy has classified the fictive motion into six categories: emanation, pattern paths, frame-relative motion, advent paths, access paths and coextension paths [1].

\section{A. Emanation}

Emanation refers to the fictive motion of intangible entities radiating from a source, which moves along an emanation path to a distal point [1]. The emanation category can further be divided into four sub-categories: orientation paths, radiation paths, shadow paths, and sensory paths. $\mathrm{Eg}^{1}$.

(5) The cliff faces towards/away from/into/past the valley.

(6) The snake is lying toward/away from the light.

(7) I pointed him toward the lobby.

The orientation paths is of a continuous linear intangible entity radiating from the facade of an object, like the cliff in (5). (5) belongs to the prospect path of the orientation paths, while (6) is the alignment path type of the orientation paths, which pertains to a stationary linear object with a point-type front. (7) is a demonstrative path type of the orientation paths, which demonstrate the direction by pointing towards the lobby.

Radiation paths is the second type of emanation, which distinguishes from others by describing the radiation from the source to the radiated object like the sun is radiating sunshine to the inside of the cave in (8).

(8) The sun is shining into the cave.

${ }^{1}$ All examples are chosen from [1] unless otherwise labelled. 
The third type of emanation is termed as shadow path. It refers to the perception of shadows of an object casting on different surfaces as if they had moved.

(9) The tree threw its shadow down into the valley.

Another type of emanation is the sensory path which comprises of two entities: the Experiencer and the Experienced. There is an intangible movement going between the two entities, each of which can be conceptualized as the source of the movement. Eg:

(10) The enemy can see us from where they're positioned.

In (10), due to the two-way quality of the light, the sight of the enemy gives the speaker perception that he could also be seen by the enemy.

\section{B. Pattern paths}

This type of sentences depicts the motion of the arrangement of some substance which is believed to be stationary or move in other ways, like the paint in (11):

(11) As I painted the ceiling, paint spots slowly progressed across the floor.

The drops on the ground definitely cannot move by themselves as soon as they reach the ground. It is the pattern of the drops that is changing with the progress.

\section{Frame-relative motion}

The frame-relative motion refers to the situation that the speaker observes the stationary surrounding as moving by adopting an observer-centered perspective. Eg. The observer is looking out of the window from a moving car. Within his frame, the observer is stationary and his surroundings including the road, the trees are moving. Hence, we have following illustrations:

(12) I sat in the car and watched the scenery rush past me.

(13) I was walking through the woods and this branch that was sticking out hit me.

\section{Advent paths}

The advent path depicts the location of stationary objects in terms of its arrival or manifestation. Take the palm trees in (14) as an example:

(14) The palm trees clustered together around the oasis.

The palm trees apparently cannot move while their pattern may seem to be formed by their arrivals in the observer's mind.

\section{E. Access paths}

The access path is utilized to describe the location of a stationary object by taking the view of an imagined entity. Eg.

(15) The bakery is across the street from the bank.

In (15), an imagined entity seems to walk across the street to reach the bank. Both the bank and the street are factive stationary objects without any movement.

\section{F. Coextension paths}

The coextension path depicts the stationary object which can spatially extend along a path, as indicated in (16):

(16) The fence goes/zigzags from the plateau to the valley.

In (16), it is actually not the fence but the eyesight or the attention of the observer that extends to the valley.

\section{COGNITIVE MOTIVATIONS OF FICTIVE MOTION}

\section{A. Talmy's view}

According to Talmy, human beings have quite a number of cognitive systems like the sensory system, memory, and language etc. All the cognitive systems are not independent from each other. Instead, they are correlated and can be regarded as a continuum. All the cognitive systems can work together under the guidance the brain and they are overlapped with each other, which he terms as "ception" [1]. Every cognitive system has its particular features which distinguish it from others, while each has the commonalities with others. Language is just one of the cognitive systems and when the linguistic representation is not consistent with its visual perception, the discrepancy may lead to the linguistic phenomenon: fictive motion. The discrepancy between the 2 cognitive systems on the same entity does not mean the 2 systems are contradictory with each other. Rather the discrepancy is due to their different perspectives toward the same object. As a result, the motion verbs are employed to depict the motionless entity, while the stationary verbs can also be utilized to describe the motion event. But there are more instances in the former, while much less in the latter, which can only exhibit human's preference for motion event rather than stationary event.

\section{B. Langacker's view}

Langacker mainly approaches the subjective motion from the perspective of cognitive grammar. According to Langacker, constructing meaning is a process of conceptualization. Language is an important tool in depicting the factual reality and those relationships in the real world. But on many occasions, those depictions are not direct, or they are indirect, just as the conversational implicature and metaphor. More importantly, human often depict the actuality by referring to the virtuality. Fictive motion is actually the speaker's mental scanning of the motionless entity [10]. Compared with Talmy, Langacker further extends the subjective motion from space to conceptualization.

\section{Lakoff's view}

Lakoff's exploration into fictive motion is mainly based on conceptual metaphor. In their viewpoint, fictive motion realizes mapping across domains and it is the linguistic representation of the metaphor FORM IS MOTION, whose source domain is motion and whose target domain is shape and form. So, fictive motion is in essence a conceptual mapping to comprehend the shape and form with motion. Sometimes, the metaphor underlay is so conventional that it has fossilized in human concepts to be clearly noticed [11]. 


\section{Fauconnier's view}

Fauconnier explains fictive motion based on the conceptual blending theory. According to this theory, there are 4 mental spaces in human's basic concepts: 2 input spaces, a generic space, and a blending space, which make up a conceptual network. To understand metaphors or difficult concepts, the listener has to map one input space to the other and together with generic space, which are blended in blending space. Through composition, completion and elaboration, a new emergent structure is produced in the blending space, which is crucial to the comprehension of linguistic phenomena [12].

\section{E. Matlock's view}

By carrying out different experiments, Matlock claims that fictive motion is actually the mental simulation of the motion in one's brain. His experimental results show that subjects dealing with sentences with fictive motion will use more time than those who do not, which can indirectly illustrate his point that people are simulate the motion in their brain and the simulation takes time [13-14].

\section{THE COGNITIVE MOTIVATIONS FROM THE PERSPECTIVE OF PHENOMENOLOGY}

Phenomenology is a 20-century philosophical school founded by Edmund Husserl which is primarily concerned with the systematic reflection and study of structure of the phenomena in the acts of consciousness [15]. Phenomenological ideas are employed by some cognitive linguists to explore the linguistic phenomenon of motion verbs to depict static situations. According to Jordan Zlatev \& Johan Blomberg [6-8], the cognitive mechanisms of the fictive motion expressions can be more appropriately and reasonably explained with the phenomenal ideas. Altogether, 3 motivations are provided for fictive motion phenomena.

\section{A. The interaction of experience and conventional semantics}

Different from the previous cognitive linguists, Zlatev \& Johan Blomberg believe that fictive motion are not unitary. That is, more than one factors contribute to the unique linguistic phenomena of motion verbs to describe static state of affairs. First of all, the cognitive mechanism for fictive motion expressions is the interaction of experience and semantics. Language is invented to express meaning, so does fictive motion expressions, whose purpose is to describe human experience. But as a linguistic form, fictive motion expressions must conform to the linguistic conventions accepted by the linguistic community. As a result, the conventionalized fictive motion forms are passed on while others forgotten. So, experience proposes meaning, but conventional semantic veto linguistic forms [6]. Convention determines the entrenched linguistic patterns. Besides, the linguistic principle of economy also plays a role in the enactment of fictive motion expressions, i.e. the original activity for which the linguistic forms are proposed to denote its connection with the meaning is deleted to designate the spatial configuration of a motion-affording entity [6]. Therefore, both the prelinguistic experience and conventional semantics and their interaction help to motivate the fictive motion expressions.

\section{B. Intersubjectivity}

Intersubjectivity was proposed by Husserl based on the dual nature of body: on the one hand as "internally" perceived subjectivity and agency, on the other as an "externally" perceived biological entity [8]. Just has the "hand" example indicates, how a human person feels as an individual towards an object could be mediated by what other people think of the same object. Hence, an individual could also perceive an entity from the perspective of others which may give rise to the following fictive motion sentences:

(17) The enemy can see us from where they are positioned[1].

(18) She can see you from her window.

(19) I must look tall to her.

The sedimented experience can be socially transferred to other members of the community, while the original activity could be buried in the sedimantation. So, the linguistic constructions, such as the fictive motion sentences, are both motivated by interaction between language and experience, and by the intersubjectivity.

\section{Imagination}

But for fictive motion sentences like the following examples, neither the personal experience could help, nor could other individuals' experience could resort to. Only the human imagination can be employed to explain the linguistic phenomena:

(20) The highway crawls through the city.

(21) Insanity runs in my family....It practically gallops! [4]

(22) There is like this snaking road up over the hills [4].

The similarity in visual sights may remind the observers of an animal, which activates the imagination in his mind. With the economy principle of language, the observer may jump over the animal and directly utilize the animals' motion to describe the shape and state of the object.

\section{CONCLUSION}

Husserl's phenomenology provides a new perspective to the cognitive motivations of fictive motion expressions. But it does not mean phenomenology will contradict all the other motivations like ception, mental scanning and mental simulation. Instead, it is a middle road between the fictive motion and other theories, which can give more reasonable explanations to fictive motion with the concepts of intersubjectivity and intentionality. In sum, fictive motion sentences are not only motivated by pre-linguistic experience, the interaction between consciousness and language, they are also motivated by intersubjectivity and imagination. 


\section{ACKNOWLEDGMENTS}

This research is financially supported by the General Project of Beijing Municipal Education Commission (No. SQSM201710015004) and the 2016 Scientific Research Project of Beijing Institute of Graphic Communication (No. 20190116002/034).

\section{REFERENCES}

[1] Talmy, Len. 2000. Toward a Cognitive Semantics, vol. 1. Cambridge, MA: MIT Press.

[2] Langacker, Ronald W. 1987. Foundations of Cognitive Grammar: Theoretical Prerequisites. Stanford, CA: Stanford University Press.

[3] Matsumoto, Y. 1996. Subjective motion and English and Japanese verbs. Cognitive Linguistics, 7 (2), 183-226.

[4] Brandt, L. 2009. Subjectivity in the act of representing: The case for subjective motion and change. Phenomenology and the Cognitive Sciences, 8(4), 573-601.

[5] Matlock, Teenie. 2010. Abstract motion is no longer abstract. Language and Cognition, 2(2), 243-260.

[6] Blomberg, Johan \& Jordan Zlatev. 2014. Actual and non-actual motion: Why experientialist semantics needs phenomenology (and vice versa). Phenomenology and the Cognitive Sciences, 13(3), 395-418.
[7] Blomberg, Johan. 2015. The expression of non-actual motion in Swedish, French and Thai. Cognitive Linguistics, 26(4), 657-696.

[8] Zlatev, Jordan \& Johan Blomberg. 2016. Embodied intersubjectivity, sedimentation and non-actual motion expressions. Nordic Journal of Linguistics 39(2), 185-208.

[9] Talmy, L. 1978. Figure and ground in complex sentences. In Joseph H. Greenberg (Ed), Universals of Human Language, Vol 4: Syntax. Stanford: Stanford University Press. 625-649.

[10] Langacker, R.W. 1999. Virtual reality, Studies in the linguistic sciences, 29: 77-103.

[11] Lakoff, G. 1987. Women, fire, and dangerous things: What categories reveal about the mind. Chicago: University of Chicago Press.

[12] Fauconnier G. \& M. Turner. The Way We Think: Conceptual Blending and the Mind's Hidden Complexities. New York: Basic books. 2002.

[13] Matlock, Teenie. 2004a. Fictive motion as cognitive simulation. Memory \& Cognition, 32(8): 1389-1400.

[14] Matlock, Teenie. 2004b. The conceptual motivation of fictive motion. In Günter Radden \& Klaus-Uwe Panther (eds.), Studies in linguistic motivation, 221-248. Berlin: Mouton de Gruyter.

[15] Husserl, Edmund. [1936]1970. The Crisis of European Sciences and Transcendental Phenomenology. Evanston, IL: Northwestern University Press. 